Revta brasil. Bot., São Paulo, V.23, n.1, p.13-26, mar. 2000

\title{
Fenologia de espécies arbóreas em floresta de planície litorânea do sudeste do Brasil ${ }^{1}$
}

\author{
DANIELA CUSTÓDIO TALORA² e PATRÍCIA C. MORELLATO ${ }^{2,3}$
}

(recebido em 10 de julho de 1998; aceito em 30 de setembro de 1999)

\begin{abstract}
Phenology of coastal-plain forest tree species from Southeastern Brazil). The present study aims to characterize the reproductive and leafing phenology of tree species of a coastal-plain forest from Southeastern Brazil and to relate the observed patterns with the local biotic and abiotic factors. The study was carried out in the Parque

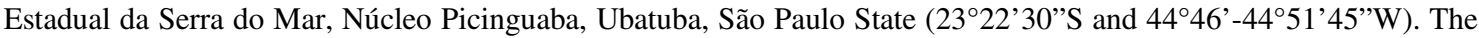
climate is tropical-wet, with a high rainfall, well distributed throughout the year. Monthly observations were carried out from July 1993 to June 1994 on 290 individuals of 46 tree species. The leaf fall was considered non-seasonal (Rayleigh test not significant), while leaf flushing $>25 \%$, flowering and fruiting were defined as weakly seasonal (Rayleigh test significant, but low $r$ values). Flowering and leaf flushing were more intense during the wetter months, from November to February. Fruit production was constant along the year. Ninety percent of the species were defined as evergreen and $87 \%$ of the species present animal-dispersed fruits. The phenological patterns observed for the coastal-plain forest at Picinguaba were weakly seasonal, contrasting with the very seasonal patterns found in the semideciduous forests from Southeastern Brazil.
\end{abstract}

RESUMO - (Fenologia de espécies arbóreas em floresta de planície litorânea do sudeste do Brasil). O presente estudo visou determinar os padrões fenológicos reprodutivos e vegetativos para espécies arbóreas da floresta superúmida de planície litorânea e relacionar os padrões observados com os fatores próximos (abióticos) e os evolutivos (bióticos). O estudo foi realizado no Parque Estadual da Serra do Mar, Núcleo Picinguaba, Ubatuba, São Paulo (2322'30"S e $\left.44^{\circ} 46^{\prime}-44^{\circ} 51^{\prime} 45^{\prime \prime} \mathrm{W}\right)$. O clima da região é tropical chuvoso, com precipitação alta e bem distribuída ao longo do ano. Observações fenológicas foram realizadas mensalmente, de julho de 1993 a junho de 1994 em 290 indivíduos pertencentes a 46 espécies arbóreas. A fenofase queda de folhas não foi sazonal (teste Rayleigh não significativo), enquanto as demais fenofases foram pouco sazonais (teste Rayleigh significativo, mas com valores baixos de r). A floração e o brotamento foram mais intensos nos meses mais úmidos, de novembro a fevereiro, enquanto a frutificação ocorreu ao longo do ano. Cerca de $90 \%$ das espécies não são decíduas, com predomínio da dispersão por animais (87\%). A floresta de planície mostrou padrões fenológicos pouco sazonais, bastante distintos dos observados para as florestas semidecíduas do interior do estado de São Paulo.

Key words - Phenology, Atlantic forest, flowering, fruiting

\section{Introdução}

A fenologia é o estudo da ocorrência de eventos biológicos repetitivos e das causas de sua ocorrência em relação às forças seletivas bióticas e abióticas e da sua inter-relação entre as fases caracterizadas por

1. Parte da dissertação de mestrado de D.C. Talora.

2. Departamento de Botânica, Universidade Estadual Paulista, Caixa Postal 199, 13506-900 Rio Claro, SP, Brasil.

3. Autor para correspondência.pmorella@ life.ibrc.unesp.br estes eventos, dentro de uma mesma ou de várias espécies (Lieth 1974). Desta forma, a fenologia contribui para o entendimento da regeneração e reprodução das plantas, da organização temporal dos recursos dentro das comunidades, das interações planta-animal e da evolução da história de vida dos animais que dependem de plantas para alimentação, como herbívoros, polinizadores e dispersores (Morellato 1991, van Schaik et al. 1993, Morellato \& Leitão-Filho 1992, 1996).

Fournier \& Sallas (1966) realizaram um dos primeiros estudos fenológicos em nível de comunidade, em espécies arbóreas de um bosque tropical seco, seguido pelo estudo de Janzen (1967), sobre o sincronismo na reprodução sexual de espécies arbóreas de floresta tropical, ambos na Costa Rica. Pos- 
teriormente, na América Central, tiveram destaque os estudos realizados por Daubenmire (1972), Frankie et al. (1974), Fournier (1976) e Opler et al. (1980), todos em florestas da Costa Rica, o de Croat (1975), no Panamá e de Bullock \& Solís-Magalhanes (1990), no México. Estes estudos mostram que a maioria das espécies arbóreas estudadas nestas comunidades apresenta o pico de floração e frutificação dentro da estação seca. Apenas o trabalho desenvolvido por Koptur et al. (1988), em floresta úmida nublada da Costa Rica, apresenta o pico de floração na transição da estação seca para a úmida.

Em florestas tropicais da América do Sul, excluindo o Brasil, encontramos o trabalho de Monasterio \& Sarmiento (1976), em uma floresta decídua e em savana tropical, e o de Lampe et al. (1992), em floresta semi-árida, ambos na Venezuela, o trabalho desenvolvido por Steege \& Persuad (1991), em floresta úmida nas Guianas e o de Hilty (1980), em vegetação pré-montana na Colômbia. Nesses casos, há uma diferença entre os padrões mais sazonais das florestas sobre clima estacional e o padrão fenológico pouco sazonal da floresta úmida estudada por Hilty (1980).

No Brasil, os estudos fenológicos em comunidades florestais ainda são restritos, sendo que alguns tipos de vegetação nunca foram considerados sob este aspecto. Na Floresta Amazônica, temos os trabalhos de Araujo (1970), Alencar et al. (1979) e Pires-O’Brien (1993). No Espírito Santo, temos um trabalho em floresta úmida não costeira, desenvolvido não através da observação direta, mas com o auxílio de coletores (Jackson 1978). Alvim \& Alvim (1976) estudaram a fenologia de mata higrófila da Bahia, que teve continuidade no trabalho desenvolvido por Mori et al. (1982), na mesma localidade. Em São Paulo, os estudos de fenologia são mais recentes, com os trabalhos de Morellato et al. (1989, 1990), Morellato \& Leitão-Filho (1990, 1992, 1996) e Morellato (1991, 1995), todos realizados em matas semidecíduas no interior do estado. Estes estudos também mostram, em geral, padrões fenológicos sazonais acompanhando a estacionalidade climática.

Morellato \& Leitão-Filho (1990, 1992, 1996), Morellato et al. $(1989,1990)$ e van Schaik et al. (1993) sugerem que vegetações com climas mais sazonais apresentam maior periodicidade na produção de flores, folhas e frutos, sendo a alternância de estações seca e úmida apontada como o principal fator envolvido no desencadeamento das fenofases. Por outro lado, Longman \& Jenik (1987) afirmam que picos e depressões nas curvas fenológicas de floração, frutificação e brotamento, não ocorrem apenas em climas com estação seca definida, mas também em florestas úmidas onde as condições climáticas variam de forma leve ou irregular.

Embora a floresta atlântica sensu stricto (Joly et al. 1992) seja bastante exuberante e, segundo Mori et al. (1981), tenha uma porcentagem alta de espécies endêmicas, esta se encontra já muito reduzida e alterada em toda a costa brasileira pela qual se estendia, sem que se tenha levantado dados fenológicos deste tipo de vegetação. Costa et al. (1992) desenvolveram um estudo fenológico preliminar para algumas espécies de floresta atlântica de altitude, na Reserva de Macaé de Cima, Rio de Janeiro. Os estudos desenvolvidos em florestas semidecíduas na Serra do Japi (Morellato et al. 1989, 1990, Morellato \& Leitão-Filho 1990, 1992), considerada por LeitãoFilho (1992) como o limite da Mata Atlântica sensu stricto, foram realizados em região de serra com clima mais sazonal, que apresenta uma estação mais seca, expondo a vegetação a períodos de estresse hídrico (Morellato et al. 1989).

O presente estudo visou determinar os padrões fenológicos reprodutivos e vegetativos para espécies arbóreas da floresta superúmida de planície litorânea (Mata Atlântica sensu stricto, Joly et al. 1992) e relacionar os padrões observados com os fatores próximos (abióticos) e os evolutivos (bióticos). Nossa hipótese de trabalho é que em florestas sob climas úmidos, com precipitação alta e bem distribuída ao longo do ano, a comunidade e suas espécies apresentarão pouca sazonalidade na ocorrência das fenofases se comparadas com florestas sob climas sazonais, com estação seca bem definida, como as florestas do interior do estado de São Paulo (Morellato et al. 1989, Morellato 1991, 1995).

\section{Material e métodos}

O estudo foi realizado no Parque Estadual da Serra do Mar, Núcleo Picinguaba, município de Ubatuba, SP,

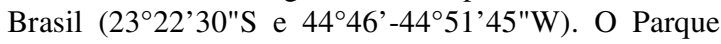
abriga diversos ecossistemas, com a altitude variando de 0 a $1.300 \mathrm{~m}$ (Cesar \& Monteiro 1995). O estudo restringiuse à planície litorânea arenosa da Praia da Fazenda, num 
hectare previamente marcado e subdividido em 100 parcelas de $10 \times 10 \mathrm{~m}$, onde foram desenvolvidos estudos fitossociológicos (Cesar \& Monteiro 1995). O hectare está localizado a cerca de $500 \mathrm{~m}$ da praia e foi considerado uma área bem preservada e representativa da vegetação a ser estudada. A vegetação estudada, floresta úmida de planície litorânea ou floresta de restinga (Cesar \& Monteiro 1995), não apresenta estratificação definida, mas percebe-se visualmente a existência de um dossel não muito fechado, com altura média entre 10 e $15 \mathrm{~m}$, caracterizado pelas espécies Pera glabrata, Eugenia brasiliensis, Alchornea triplinervea, Myrcia racemosa, Nectandra oppositifolia, Jacaranda puberula, Euplassa cantareirae e Rapanea umbellata (para autoria dos nomes científicos, ver tabela 1). O subdossel é denso, caracterizado por Euterpe edulis, Guatteria australis e Guarea macrophylla, além de espécies tipicamente arbustivas e herbáceas das famílias Rubiaceae, Piperaceae e Bromeliaceae. Grande número de epífitas (Bromeliaceae, Araceae e Orchidaceae) ocorre principalmente nas árvores de grande porte. O solo é coberto por serrapilheira e possui canais de drenagem superficiais, permanecendo alagado durante os meses de maior precipitação.

O clima da região de Ubatuba, segundo classificação proposta por Koeppen (1948), pode ser definido como clima de floresta tropical chuvosa (Af), constantemente úmido, com chuvas suficientes todos os meses. Os dados de precipitação atmosférica obtidos junto ao Instituto Agronômico de Campinas (IAC) para o município de Ubatuba, SP, para o período de 1961 a 1990, apontam para a existência de dois períodos durante o ano, um superúmido, de outubro a abril, com chuvas freqüientes (15 ou mais dias no mês) e total geralmente superior aos $180 \mathrm{~mm}$ mensais, e outro menos úmido, de maio a setembro, e com chuvas menos constantes (em geral 10 dias ao mês), embora sem déficit hídrico, com precipitação entre 80 e $160 \mathrm{~mm}$ mensais. Segundo Wright \& van Shaik (1994), florestas com média de pluviosidade acima de $60 \mathrm{~mm}$ no mês mais seco podem ser definidas como fracamente sazonais. Dentro da estação mais chuvosa, a maior precipitação ocorre entre dezembro e março, com valores médios entre 300 a $340 \mathrm{~mm}$ mensais, época em que os solos são passíveis de inundação. A precipitação média anual é de, aproximadamente, $2.600 \mathrm{~mm}$ e a umidade relativa do ar é sempre superior a $85 \%$. A temperatura média anual gira em torno dos $21^{\circ} \mathrm{C}$, com a média das máximas em fevereiro $\left(30,4^{\circ} \mathrm{C}\right)$ e a média das mínimas em julho $\left(12,6^{\circ} \mathrm{C}\right)$. O comprimento do dia em horas varia de 13,47 h.dia ${ }^{-1} \mathrm{em}$ dezembro a 10,55 h.dia ${ }^{-1}$ em junho, variando em 2,92 h, durante o ano. A insolação média diária é de 4,3 h, sendo fevereiro o mês com maior número de horas de insolação $\left(5,1\right.$ h.dia $\left.{ }^{-1}\right)$ e outubro o mês com menor $\left(2,9\right.$ h.dia $\left.{ }^{-1}\right)$, indicando que o céu se apresenta encoberto por nuvens em grande parte do dia. O período de menor temperatura coincide com os meses menos chuvosos do ano e com os menores comprimentos do dia. Durante o período em que o presente trabalho foi desenvolvido, o mês de menor precipitação foi agosto de 1993 (18,9 mm), caracterizando um período seco raro na região de estudo (figura 1). $\mathrm{O}$ ano de 1993 teve precipitação atmosférica menor do que a média da região $(2.249 \mathrm{~mm})$, enquanto os anos de $1992 \mathrm{e}$ 1994 apresentaram, respectivamente, precipitação total de 2.853 e $2.836 \mathrm{~mm}$, valores acima da média.

As observações fenológicas foram realizadas mensalmente, com o auxílio de binóculos, durante os meses de julho de 1993 a junho de 1994. Observações fenológicas preliminares foram realizadas no período de agosto de 1992 a junho de 1993. Estes dados foram utilizados para auxiliar na determinação dos padrões de floração e frutificação das espécies. Foram amostrados indivíduos arbóreos, com perímetro mínimo de $10 \mathrm{~cm}$ a altura do peito, totalizando 290 indivíduos pertencentes a 46 espécies arbóreas. $\mathrm{O}$ número de espécies observado neste trabalho representa $62 \%$ do total de espécies arbóreas amostradas no estudo fitossociológico desenvolvido por Cesar \& Monteiro (1995). Foram acompanhados 1 a 23 indivíduos por espécie, média de 6,1 indivíduos por espécie, dentro da média sugerida por Frankie et al. (1974) e Fournier \& Charpantier (1975). As fenofases observadas foram floração, frutificação, queda foliar e brotamento, do início até o final de cada uma, utilizando-se para a construção das curvas fenológicas a definição proposta por Morellato et al. (1989), onde a produção de flores é dividida em botões e floração propriamente dita ou período de antese, e a produção de frutos em período de desenvolvimento dos frutos ou frutos verdes e a frutificação propriamente dita ou período de frutos maduros e prontos para a dispersão. Cada fenofase foi quantificada utilizando-se quatro categorias de amplitude de $25 \%$ cada. A determinação dos padrões de produção e queda de folhas seguiu a classificação proposta por Morellato et al. (1989), constituída por três categorias: decídua, semidecídua e perenifólia. Como as fenofases queda foliar e brotamento foram constantes ao longo do ano, mas com um nível de resposta bem baixo, estes dados são apresentados de duas formas: (1) ocorrência dos fenômenos a partir de $1 \%$ em pelo menos um indivíduo da espécie observada (categoria 1:1 a 25\%); (2) o fenômeno só foi considerado se pelo menos um indivíduo da espécie apresentasse $26 \%$ ou mais de intensidade do fenomêno (categoria 2:26 a 50\%) em um determinado mês. Esta metodologia foi utilizada por Koptur et al. (1988) em estudos fenológicos realizados em floresta úmida da Costa Rica. As espécies foram agrupadas segundo seu modo de dispersão, conforme os critérios adotados por Morellato \& Leitão-Filho (1992). 
Com referência à análise de dados, para testar o tipo de distribuição, foi realizado o teste de Shapiro e Wilks (Zar 1996). Como os dados não mostraram distribuição normal, partiu-se para o uso da estatística não-paramétrica. Foi calculada a correlação de Spearman $\left(\mathrm{r}_{\mathrm{s}}\right)$, (Zar 1996) entre o número de espécies em cada fenofase, por mês e as variáveis climáticas no mesmo período: temperatura média, máxima e mínima absolutas, média das máximas e das mínimas, pluviosidade, comprimento do dia e horas de insolação diárias. Como as correlações entre as fenofases e as temperaturas apresentaram resultados semelhantes, serão apresentados apenas os valores de correlação com a temperatura média. Foi utilizado o teste de Rayleigh (Z) para distribuição circular (Morellato et al. 1989, Zar 1996), calculando-se as datas médias para a frequiência de espécies em floração, frutificação, queda foliar e brotamento (v. observações em Morellato et al. 1989), e a concentração de cada evento em torno desta data (r). As distribuições de frequiências das espécies em cada fenofase foram plotadas em histogramas circulares, para intervalos mensais, com os 365 dias do ano correspondendo aos $360^{\circ}$ da circunferência, sendo o dia primeiro de julho correpondente ao $15^{\circ}$ e cada período de 30 dias a $30^{\circ}$. O comprimento do vetor relaciona-se com o valor do coeficiente de concentração (r), que varia de 0 a 1 , e o ângulo em que este é plotado indica o ângulo médio, que corresponde à data média de ocorrência da fenofase.

\section{Resultados}

Queda foliar e brotamento - A vegetação da floresta de planície litorânea mudou pouco de aspecto durante $o$ ano. A queda foliar foi praticamente constante ao longo do ano, com valores variando entre 90 a $100 \%$ das espécies perdendo folhas a cada mês, sempre em pequena intensidade (tabela 1, figura 2A). Quando foi usado um mínimo de $26 \%$ de atividade em pelo menos um indivíduo da população para registro da ocorrência do fenômeno, a variação na produção e queda das folhas foi maior (figura 2B). No início do período mais úmido e quente, em outubro, foi observado o maior número de espécies perdendo folhas (21 espécies), sendo que em março foi observado o menor número de espécies perdendo folhas (seis espécies). Nos demais meses do ano, a queda foliar oscilou entre 11 e 18 espécies perdendo folhas por mês (figura 2B). Os coeficientes de Spearman mostraram que a queda foliar apresentou correlação negativa significativa com a pluviosidade $\left(\mathrm{r}_{\mathrm{s}}=-0,79 ; \mathrm{p}<0,01\right)$ e com a temperatura média $\left(r_{s}=-0,61 ; p<0,05\right)$. Os valores do teste de
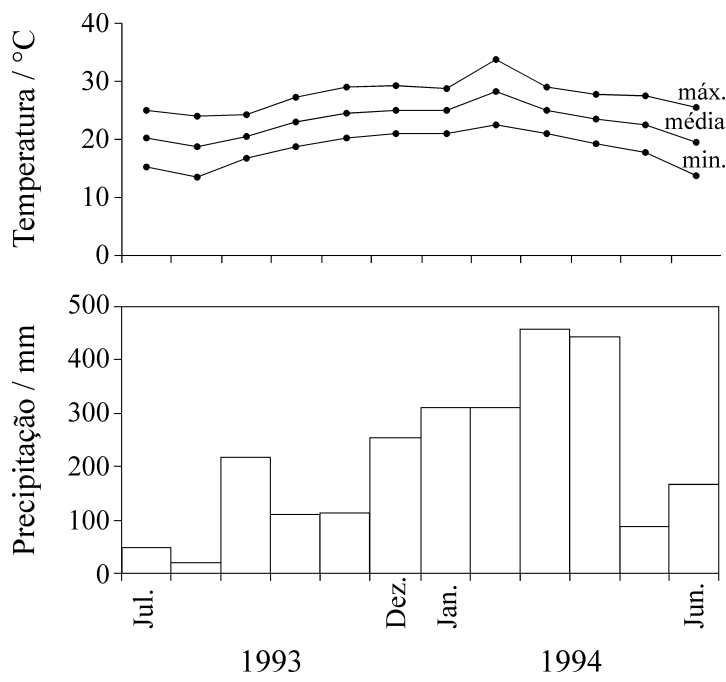

Figura 1. Distribuição da precipitação e temperaturas durante o período de estudo (julho/1993 a junho/1994), na região de Ubatuba. Fonte: Instituto Agronômico de Campinas.

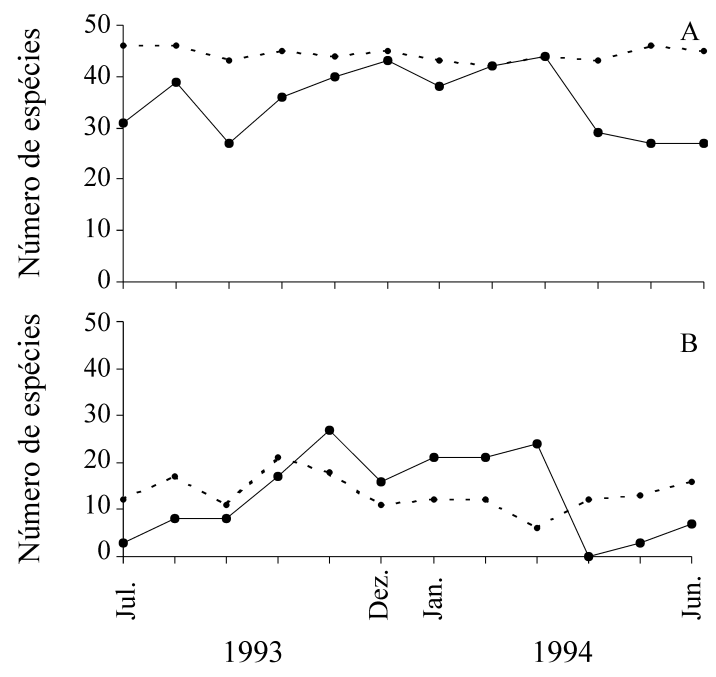

Figura 2. Número de espécies arbóreas apresentando queda de folhas e brotamento em floresta de planície litorânea, Núcleo Picinguaba, Ubatuba, SP. A. Queda foliar (- - - -) e brotamento (- - -). B. Queda foliar (- - - -) e brotamento (- - ) para os $26 \%$ mínimos de intensidade. Queda foliar $>25 \%$; Brotamento $>25 \%$.

Rayleigh mostraram que não há data média para a queda foliar (tabela 2; figuras 4A e 4B). 
Tabela 1. Comportamento fenológico, modo de dispersão e deciduidade das espécies da floresta de planície litorânea, Núcleo Picinguaba, Ubatuba, SP. - - fenofase não observada.

\begin{tabular}{|c|c|c|c|c|c|}
\hline $\begin{array}{l}\text { FAMÍLIAS } \\
\text { Espécies }\end{array}$ & Floração & Frutificação & $\begin{array}{c}\text { Queda } \\
\text { foliar(**) }\end{array}$ & $\begin{array}{l}\text { Brota- } \\
\text { mento }\end{array}$ & $\begin{array}{l}\text { Modo de } \\
\text { dispersão }\end{array}$ \\
\hline \multicolumn{6}{|l|}{ ANACARDIACEAE } \\
\hline Tapirira guianensis Aubl. & -- & -- & ano todo & mar & animal \\
\hline \multicolumn{6}{|l|}{ ANNONACEAE } \\
\hline Guatteria australis St.Hill. & nov-mar & nov- jun & ano todo & ano todo & animal \\
\hline \multicolumn{6}{|l|}{ AQUIFOLIACEAE } \\
\hline Ilex dumosa Reiss. & -- & -- & ano todo & ano todo & animal \\
\hline Ilex integerrima (Vell.) Reiss. & -- & -- & ano todo & dez-mai & animal \\
\hline \multicolumn{6}{|l|}{ ARALIACEAE } \\
\hline Didymopanax calvum Dene et Planchon & mar-mai & out-jan, jul & ano todo & ano todo & animal \\
\hline \multicolumn{6}{|l|}{ ARECACEAE } \\
\hline Euterpe edulis Mart. & out-dez & nov-jul & ano todo & ano todo & animal \\
\hline \multicolumn{6}{|l|}{ BIGNONIACEAE } \\
\hline Jacaranda puberula Cham. & out-nov & jan-fev & jun-out ${ }^{1}$ & set-out & vento \\
\hline \multicolumn{6}{|l|}{ CAESALPINIACEAE } \\
\hline Sclerolobium denudatum Vog. & jul-set & jun & ano todo & nov-mar & vento \\
\hline \multicolumn{6}{|l|}{ CELASTRACEAE } \\
\hline Maytenus brasiliensis Mart. & nov-dez & jul-ago, mar-abr & ano todo & ano todo & animal \\
\hline Maytenus ubatubensis Car. Okano & out-nov & jul-jan & ano todo & nov-mar & animal \\
\hline \multicolumn{6}{|l|}{ CHRYSOBALANACEAE } \\
\hline Hyrtella hebeclada Moric. & jan-fev $(*)$ & jul-ago & ano todo & ago-out & animal \\
\hline \multicolumn{6}{|l|}{ CLUSIACEAE } \\
\hline $\begin{array}{l}\text { Clusia criuva } \text { Camb. } \\
\text { população feminina } \\
\text { população masculina }\end{array}$ & $\begin{array}{l}\text { jan }(*) \\
\text { nov-jan }\end{array}$ & fev(*), abr & $\begin{array}{l}\text { ano todo } \\
\text { ano todo }\end{array}$ & $\begin{array}{l}\text { ano todo } \\
\text { ano todo }\end{array}$ & animal \\
\hline Kielmeyera petiolares Mart. & -- & mai-jun ${ }^{(*)}$,jul & ano todo & ano todo & vento \\
\hline $\begin{array}{l}\text { Rheedia brasiliensis (Mart.) Planchon } \\
\text { et Triana }\end{array}$ & -- & -- & ano todo & ano todo & animal \\
\hline \multicolumn{6}{|l|}{ EUPHORBIACEAE } \\
\hline Alchornea triplinervea (Spreng.) M. Arg. & nov-dez & ago, jan, mai-jun & ano todo & ano todo & animal \\
\hline Margaritaria nobilis L.F. & $\operatorname{abr}-$ jun $(*)$ & jun-ago & ano todo & set-mai & autocoria \\
\hline $\begin{array}{l}\text { Pera glabrata }(\text { Schott) Baill. } \\
\text { população feminina } \\
\text { população masculina }\end{array}$ & $\begin{array}{l}\text { jan-fev, abr-mai } \\
\text { jan-fev, abr }\end{array}$ & jul-set, abr-jun & $\begin{array}{l}\text { ano todo } \\
\text { ano todo }\end{array}$ & $\begin{array}{l}\text { jul-abr } \\
\text { jul-abr }\end{array}$ & animal \\
\hline \multicolumn{6}{|l|}{ FABACEAE } \\
\hline Andira fraxinifolia Benth. & mai & jun-jul & ano todo & nov-abr & animal \\
\hline $\begin{array}{l}\text { Swartzia simplex var. grandiflora } \\
\text { (Raddi) Cowan. }\end{array}$ & -- & jul-out & ano todo & ano todo & animal \\
\hline \multicolumn{6}{|l|}{ LAURACEAE } \\
\hline Endlicheria paniculata (Spreng.) Mcbride & -- & ago-set & ano todo & ano todo & animal \\
\hline Nectandra oppositifolia Ness. & mar-mai & $\operatorname{abr-jun}(*)$ & ano todo & ano todo & animal \\
\hline
\end{tabular}




\begin{tabular}{|c|c|c|c|c|c|}
\hline $\begin{array}{l}\text { FAMÍLIAS } \\
\text { Espécies }\end{array}$ & Floração & Frutificação & $\begin{array}{c}\text { Queda } \\
\text { foliar(**) }\end{array}$ & $\begin{array}{l}\text { Brota- } \\
\text { mento }\end{array}$ & $\begin{array}{l}\text { Modo de } \\
\text { dispersão }\end{array}$ \\
\hline \multicolumn{6}{|l|}{ MELASTOMATACEAE } \\
\hline Miconia dodecandra (Desc.) Cogn. & ano todo & ano todo & ano todo & ano todo & animal \\
\hline Miconia prasina (Sw.) D.C. & -- & jun $(*)$, jul & ano todo & nov-mar & animal \\
\hline Miconia rigidiuscula Cogn. & mar-jun & mai-ago & ano todo & ago-abr & animal \\
\hline Tibouchina pulchra Cogn. & jul-set, dez-mai & ano todo & ano todo & dez-jun & vento \\
\hline \multicolumn{6}{|l|}{ MELIACEAE } \\
\hline Cabralea canjerana (Vell.) Mar. & -- & -- & ano todo & nov-jun & animal \\
\hline $\begin{array}{l}\text { Guarea macrophylla subsp. tuberculata } \\
\text { (Vell.) Penn. }\end{array}$ & dez-abr & abr-jul & ano todo & ano todo & animal \\
\hline \multicolumn{6}{|l|}{ MIMOSACEAE } \\
\hline Inga edulis Mart. & nov-abr & -- & ano todo & ano todo & animal \\
\hline Inga luschnatiana Benth. & mar-abr & - & nov-jul & ago-fev & animal \\
\hline Inga marginata Willd. & - - & - & ano todo & ano todo & animal \\
\hline Macrosamania pedicellaris (DC.) Kleinh. & dez-jan & fev-mar & $\operatorname{mar}^{1}$ & dez-mai & vento \\
\hline \multicolumn{6}{|l|}{ MYRSINACEAE } \\
\hline Rapanea ferruginea (Ruiz \& Pav.) Mez. & mai-jun & jun $(*)$ & ano todo & jun-mar & animal \\
\hline $\begin{array}{l}\text { Rapanea umbellata (Mart.) Mez. } \\
\text { população feminina } \\
\text { população masculina }\end{array}$ & $\begin{array}{l}\text { nov, mai-jun } \\
\text { nov, mai }\end{array}$ & jul-jan & $\begin{array}{l}\text { ano todo } \\
\text { ano todo }\end{array}$ & $\begin{array}{l}\text { jul-abr } \\
\text { ano todo }\end{array}$ & animal \\
\hline \multicolumn{6}{|l|}{ MYRTACEAE } \\
\hline Eugenia brasiliensis var. silvestris Mart. & dez-jan & fev-jul & ano todo & out-jun & animal \\
\hline Eugenia schuchiana Berg. & jan-fev & jul-ago, jan & ano todo & dez-jun & animal \\
\hline Eugenia umbelliflora Berg. & jan & -- & ano todo & ano todo & animal \\
\hline Marlierea tomentosa (DC.) Kiaersk & abr-jul & - & ano todo & ago-abr & animal \\
\hline Myrcia fallax (Richard) DC. & ago-set & out & ano todo & jul-mar & animal \\
\hline Myrcia multiflora (Lamark) DC. & dez-jan & jan-fev & ano todo & jul-abr & animal \\
\hline Myrcia racemosa (Berg) Kiaersk & ago-set, dez-jan & out-dez, mai-jun & ano todo & ano todo & animal \\
\hline Psidium cattleyanum Sabine & - & - & mai-set $^{2}$ & out-mar & animal \\
\hline Syzygium jambos (L.) Alston & jul-ago & out & ano todo & jul-mar & animal \\
\hline \multicolumn{6}{|l|}{ NYCTAGINACEAE } \\
\hline Guapira opposita (Vell.) Reitz & dez & -- & ano todo & ano todo & animal \\
\hline \multicolumn{6}{|l|}{ POLYGONACEAE } \\
\hline Coccoloba alnifolia & -- & -- & jun-out $^{2}$ & nov-mai & animal \\
\hline \multicolumn{6}{|l|}{ PROTEACEAE } \\
\hline Euplassa cantareirae Sleum & mar-abr & jun-set & ano todo & jul-abr & animal \\
\hline \multicolumn{6}{|l|}{ RUBIACEAE } \\
\hline Amaioua intermedia Mart. & -- & -- & ano todo & jul-abr & animal \\
\hline
\end{tabular}

(*) dados preliminares coletados no ano anterior.

(**) ${ }^{1}$ decídua; ${ }^{2}$ semidecídua; sem marcação: sempre verdes ou não decíduas. 
A produção de folhas também foi uma atividade constante, presente em mais de $50 \%$ das espécies durante todo o ano, porém sempre ocorrendo com baixa intensidade (figura 2A) com valores máximos no período mais úmido, entre novembro e março (acima de 80\% das espécies) e mínimos em maio, junho e setembro (aproximadamente $60 \%$ das espécies), coincidindo com o período mais seco e frio. $\mathrm{O}$ brotamento apresentou correlação significativa positiva com a temperatura $\left(r_{s}=0,69 ; p<0,05\right)$ e com o comprimento do dia $\left(\mathrm{r}_{\mathrm{s}}=0,68 ; \mathrm{p}<0,05\right)$. Usando o critério dos $26 \%$ mínimos de atividade, a curva de brotamento foi semelhante, mas as inflexões se acentuaram. O período com maior número de espécies brotando (16 a 27) ocorreu de novembro a março, com o pico em novembro (figura $2 \mathrm{~B}$ ). Em abril e maio, ocorreu uma queda brusca no número de espécies brotando com aumento gradual a partir de agosto. O brotamento para $26 \%$ mínimos de atividade mostrou correlação positiva significativa com o comprimento do dia $\left(r_{s}=0,73, p<0,01\right)$ e temperatura $\left(r_{s}=0,61 ; p<0,05\right)$, e apresentou o maior valor de $r$ de todas as fenofases no teste de Rayleigh (tabela 2; figura 4D), com data média em 24 de dezembro, embora este valor de $r$ possa ser considerado baixo. A curva encontrada para a queda foliar dos $26 \%$ mínimos precedeu a encontrada para o brotamento dos 26\% mínimos em aproximadamente um mês (figura 2B), sugerindo uma relação entre estas fenofases.

Padrões de produção de folhas - Das 46 espécies estudadas, 42 (91,3\%) foram incluídas na categoria das perenifólias, duas $(4,3 \%)$ foram consideradas semidecíduas (Cocolloba alnifolia e Psidium cattleyanum), e as outras duas $(4,3 \%)$ foram consi-

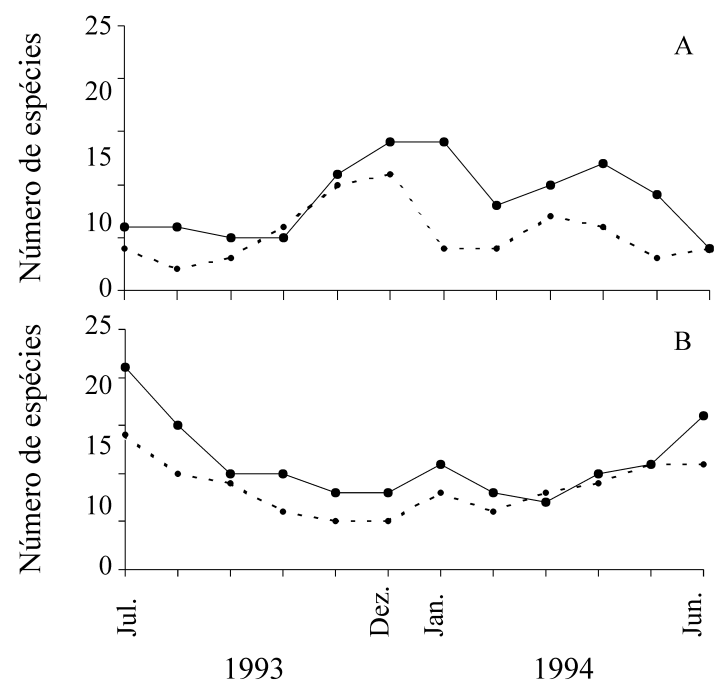

Figura 3. Número de espécies arbóreas em A. Botão (- - • - -) e antese (- - - ). B. Frutos verdes (- - - -) e frutos maduros (-—), em floresta de planície litorânea, Núcleo Picinguaba, Ubatuba, SP.

deradas decíduas (tabela 1). Entre as decíduas, Macrosamania pedicellaris se comportou como decídua no primeiro ano de observação (dez/92) e como semidecídua no segundo ano (mar/94), quando a desfolha e o brotamento foram menos concentrados, embora indivíduos não marcados mantivessem o comportamento decíduo.

Floração - Durante o período de estudo, 12 espécies $(26,1 \%)$ das 46 observadas não floresceram (tabela 1). Duas destas espécies, I. marginata e $P$. cattleyanum, floresceram neste período na planície litorânea, mas não na área de estudo. As espécies Swartzia simplex, Endlicheria paniculata, Miconia dodecandra e Rapanea ferruginea não foram obser-

Tabela 2. Valores estimados para as distribuições circulares das fenofases estudadas na floresta de planície litorânea, Núcleo Picinguaba, Ubatuba, SP, onde: $\mathrm{Br}>25 \%=$ brotamento acima de $25 \%$ de intensidade e QF $>25 \%=$ queda foliar acima de $25 \%$ de intensidade.

\begin{tabular}{lcccccc}
\hline & Queda foliar & QF $>25 \%$ & Brotamento & Br $>25 \%$ & Floração & Frutificação \\
\hline Concentração (r) & 0,01 & 0,11 & 0,09 & 0,39 & 0,22 & 0,18 \\
Ângulo médio & $26 \pm 90^{\circ}$ & $86 \pm 80^{\circ}$ & $180 \pm 90^{\circ}$ & $174 \pm 17^{\circ}$ & $209 \pm 40^{\circ}$ & $14 \pm 43^{\circ}$ \\
Data média & $26 / 07$ & $26 / 09$ & $31 / 12$ & $24 / 12$ & $29 / 01$ & $14 / 07$ \\
Rayleigh Z & 0,09 & 1,80 & 3,73 & 24,10 & 4,91 & 4,66 \\
$\mathrm{p}$ & $\mathrm{ns}$ & $\mathrm{ns}$ & $\mathrm{ns}$ & $\mathrm{p}<0,001$ & $0,01<\mathrm{p}<0,02$ & $0,01<\mathrm{p}<0,02$ \\
\hline
\end{tabular}

ns = não significativo. 

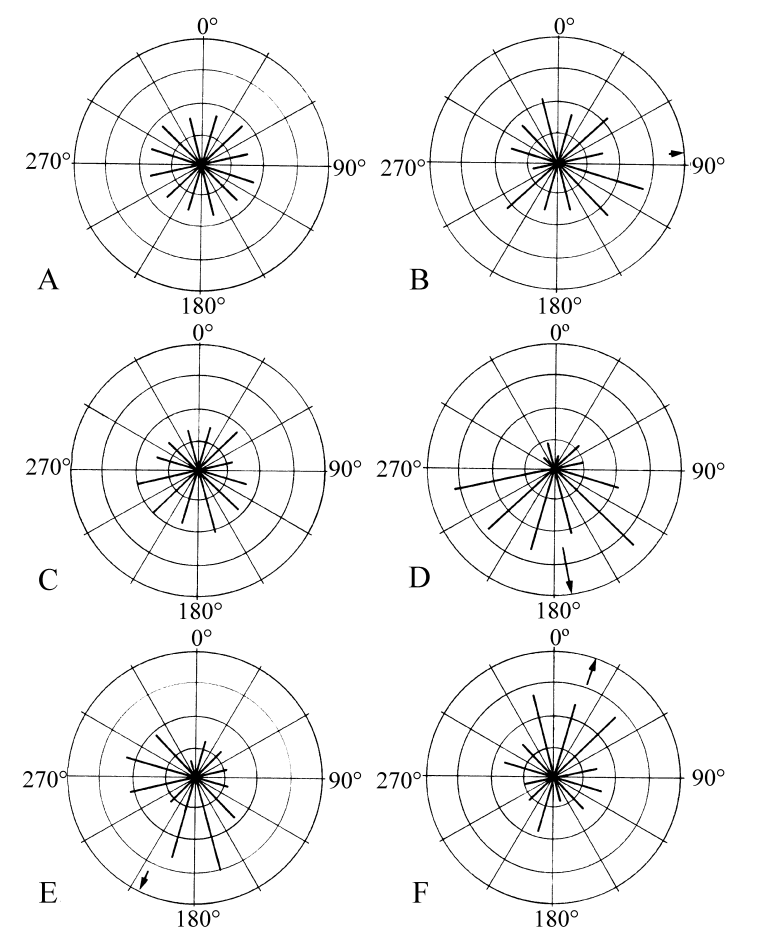

Figura 4. Histogramas circulares de frequência relativa mensal de espécies em cada fenofase na floresta de planície litorânea, Núcleo Picinguaba, Ubatuba, SP. Fenofases: A. Queda foliar; B. Queda foliar para os $26 \%$ mínimos de intensidade; C. Brotamento; D. Brotamento para os $26 \%$ de intensidade; E. Floração; F. Frutificação.

vadas com flores por já apresentarem frutos quando incluídas na observação, não florescendo até o final das observações. Hyrtela hebeclada e Margaritaria nobilis floresceram no ano de observações preliminares, mas não floresceram no ano seguinte.

Embora fossem observadas espécies florescendo durante $\mathrm{o}$ ano todo, o ritmo de produção de flores apresentou leve sazonalidade (figura $3 \mathrm{~A}$ ). $\mathrm{O}$ número de espécies em flor começou a aumentar a partir de novembro, no período mais quente e úmido do ano e com aumento no fotoperíodo, com o pico em dezembro/janeiro, decaindo em junho, já no período mais frio e menos úmido. $\mathrm{O}$ número mínimo de espécies florescendo foi de quatro em junho e o máximo de 14 em dezembro e janeiro. Houve correlação significativa positiva entre o número de espécies em antese e o comprimento do dia $\left(\mathrm{r}_{\mathrm{s}}=0,64\right.$; $\mathrm{p}<0,05)$ e com a temperatura média $\left(\mathrm{r}_{\mathrm{s}}=0,68\right.$; $\mathrm{p}<0,05)$. Analisando-se a produção de botões, esta acompanhou a curva de floração (figura 3A), mostrando correlação significativa positiva com a temperatura média $\left(r_{s}=0,64 ; p<0,05\right)$. O teste de Rayleigh foi significativo, e a data média de ocorrência da floração foi 29 de janeiro (tabela 2; figura 4E). Frutificação - Das 46 espécies estudadas, 32 (69,6\%) frutificaram durante o período de estudo (tabela 1). A frutificação também apresentou leve sazonalidade (figura 3B). O maior número de espécies com frutos maduros (15 a 21) ocorreu entre os meses de junho a agosto, coincidindo com o período mais frio e menos úmido, oscilando entre 11 e sete nos demais meses (figura 3B). O número mínimo de espécies com fruto maduro (quatro) ocorreu em dezembro. A frutificação apresentou correlação negativa significativa com a pluviosidade $\left(\mathrm{r}_{\mathrm{s}}=-0,61 ; \mathrm{p}<0,05\right)$, com o comprimento do dia $\left(r_{s}=-0,70 ; p<0,05\right)$, correlação negativa altamente significativa com a temperatura média $\left(r_{s}=-0,82 ; p<0,001\right)$. A curva de produção de frutos verdes acompanhou a de frutificação (figura 3B). Foi observada correlação negativa altamente significativa entre frutos verdes e o comprimento do dia $\left(r_{\mathrm{s}}=-0,92 ; \mathrm{p}<0,001\right)$ e significativa com a temperatura média $\left(r_{s}=-0,78 ; p<0,01\right)$. $O$ teste de Rayleigh foi significativo e a data média de frutificação foi 14 de julho (tabela 2; figura 4F).

Das 46 espécies estudadas, $40(86,9 \%)$ apresentaram dispersão por animal, cinco $(10,9 \%)$ pelo vento e apenas uma (2,2\%), Margaritaria nobilis, é autocórica (tabela 1). As espécies anemocóricas estudadas na vegetação de planície litorânea de Picinguaba são comuns no estrato superior da floresta. As espécies dispersas por animais frutificaram o ano todo, sucedendo-se ao longo do período de observação (tabela 3 ). $O$ teste do $X^{2}$ realizado para as espécies com esta síndrome de dispersão demonstrou não haver diferença significativa entre os números de espécies zoocóricas com frutos por mês esperados e os encontrados $\left(X^{2}=12,78 ; \mathrm{p}<0,01\right)$.

Relação entre fenofases - Houve correlação significativa negativa entre o número de espécies brotando e o número de espécies com frutos verdes $\left(\mathrm{r}_{\mathrm{s}}=-0,69\right.$; $\mathrm{p}<0,05)$ e com frutos maduros $\left(\mathrm{r}_{\mathrm{s}}=-0,68\right.$; $\mathrm{p}<0,05)$. Também foi observada correlação negativa significativa entre o brotamento para os $26 \%$ mínimos de ocorrência e frutos maduros $\left(\mathrm{r}_{\mathrm{s}}=-0,66\right.$; $\mathrm{p}<0,05)$, e frutos verdes $\left(\mathrm{r}_{\mathrm{s}}=-0,77 ; \mathrm{p}<0,01\right)$. A produção de botões apresentou correlação negativa 
Tabela 3. Frutificação das espécies dispersas por animais na floresta de planície litorânea, Núcleo Picinguaba, Ubatuba, $\mathrm{SP}$, ordenadas de acordo com o início da fenofase.

\begin{tabular}{|c|c|c|c|c|c|c|c|c|c|c|c|c|}
\hline Espécie & $\begin{array}{c}\text { Jul } \\
1993 \\
\end{array}$ & Ago & Set & Out & Nov & Dez & $\begin{array}{c}\text { Jan } \\
1994 \\
\end{array}$ & Fev & Mar & Abr & Mai & Jun \\
\hline Nectandra oppsitifolia & & & & & & & & & & & & \\
\hline Eugenia schuchiana & & & & & & & & & & & & \\
\hline Hyrtella hebeclada & & & & & & & & & & & & \\
\hline Maytenus brasiliensis & & & & & & & & & & & & \\
\hline Euplassa cantareirae & & & & & & & & & & & & \\
\hline Maytenus ubatubensis & & & & & & & & & & & & \\
\hline Swartzia simplex & & & & & & & & & & & & \\
\hline Alchornea triplinervea & & & & & & & & & & & & \\
\hline Endlicheria paniculata & & & & & & & & & & & & \\
\hline Syzygium jambos & & & & & & & & & & & & \\
\hline Myrcia fallax & & & & & & & & & & & & \\
\hline Rapanea umbellata & & & & & & & & & & & & \\
\hline Myrcia racemosa & & & & & & & & & & & & \\
\hline Didymopanax calvum & & & & & & & & & & & & \\
\hline Myrcia multiflora & & & & & & & & & & & & \\
\hline Eugenia brasiliensis & & & & & & & & & & & & \\
\hline Clusia criuva & & & & & & & & & & & & \\
\hline Guarea macrophylla & & & & & & & & & & & & \\
\hline Pera glabrata & & & & & & & & & & & & \\
\hline Miconia rigidiuscula & & & & & & & & & & & & \\
\hline Guatteria australis & & & & & & & & & & & & \\
\hline Euterpe edulis & & & & & & & & & & & & \\
\hline Miconia dodecandra & & & & & & & & & & & & \\
\hline
\end{tabular}

muito significativa com a produção de frutos verdes $\left(\mathrm{r}_{\mathrm{s}}=-0,70 ; \mathrm{p}<0,01\right)$ e negativa significativa com os frutos maduros $\left(r_{s}=-0,65 ; p<0,05\right)$, mas não apresentou correlação significativa com a antese. Frutos verdes e frutos maduros apresentaram correlação positiva altamente significativa $\left(r_{\mathrm{s}}=0,82\right.$; $\mathrm{p}<0,001)$.

\section{Discussão}

As fenofases estudadas apresentaram várias correlações significativas com as variáveis climáticas, indicando que mesmo os fatores ambientais sendo pouco sazonais na área de estudo, estes ainda exercem influência sobre as fenofases das espécies observadas, embora de maneira menos evidente do que em matas cujo clima apresenta sazonalidade maior. Trabalhos realizados por Frankie et al. (1974), Hilty (1980), Koptur et al. (1988) e Morellato \& LeitãoFilho (1990) sugerem que, em ambientes pouco sazonais, os fatores ambientais devem ter menor influência sobre as fenofases do que em ambientes notadamente sazonais. Além dos fatores climáticos, processos endógenos da planta e pressões seletivas bióticas devem influenciar a periodicidade das fenofases das espécies de mata atlântica deste estudo. 
Borchert (1980) sugere que padrões de reprodução e crescimento em espécies tropicais são determinados primariamente por processos periódicos endógenos e só secundariamente como adaptação às mudanças ambientais. Aide (1988) considera que, em ambientes cuja sazonalidade climática é pouco pronunciada, os determinantes da fenologia vegetal devem incluir pressões seletivas bióticas, tais como pressão de herbívoros, predadores, competidores, polinizadores e dispersores.

Fenofases pouco relacionadas a uma determinada época do ano: queda foliar e frutificação - O clima pouco sazonal de Picinguaba parece favorecer a estratégia de perda e reposição de poucas folhas durante todo o ano. Jackson (1978) sugere que, para plantas perenes, em ambientes sujeitos a baixa sazonalidade climática, sem estação seca severa, a queda foliar e o brotamento contínuos seriam as estratégias mais vantajosas, pois permitiriam que a folha velha fosse mantida na árvore até ser realizada a translocação de nutrientes, além de possibilitar a manutenção da taxa fotossintética o ano todo. Koptur et al. (1988) encontrou padrão de queda foliar semelhante ao observado em Picinguaba, numa floresta úmida de altitude na Costa Rica, de clima pouco sazonal. Muitas espécies da floresta de planície litorânea de Picinguaba apresentaram aumento de queda foliar no período de menor umidade, fotoperíodo e temperatura. Borchert (1980) afirma que condições climáticas constantes não existem no mundo, e que o excesso de evapotranspiração sobre a precipitação, ocorrentes mesmo nos ambientes mais úmidos, deve ser suficiente para sincronizar a queda foliar e mesmo o subsequiente brotamento ou floração em muitas árvores. De fato, o padrão de queda foliar tem sido freqüentemente associado a sazonalidade climática. Ambientes que apresentam sazonalidade climática marcada, com uma estação seca bem definida, costumam apresentar desfolha concentrada nesta época do ano (Janzen 1967, Araujo 1970, Daubenmire 1972, Frankie et al. 1974, Fournier 1976, Monasterio \& Sarmiento 1976, Morellato et al. 1989, Morellato 1995).

A frutificação, ocorrente durante o ano todo, sugere que ambientes com baixa sazonalidade climática, como a região estudada, oferecem condições pouco restritivas para o desenvolvimento e amadurecimento dos frutos durante o ano todo. Esta idéia é reforçada pela ocorrência do pico de frutificação no período de menor pluviosidade e pela correlação negativa entre frutos maduros e pluviosidade. Esta produção contínua de frutos dispersos predominantemente por animais na floresta estudada tem sido freqüentemente associada a uma estratégia para a manutenção de recursos aos animais dispersores de sementes (Snow 1965, Hilty 1980). Snow (1965) aponta a diminuição na competição por dispersores como vantagem para um padrão contínuo de frutificação na comunidade.

Mesmo com os frutos produzidos o ano todo, houve data média significativa de produção de frutos, durante o período mais frio e de menor pluviosidade, e correlações negativas significativas com a temperatura, o comprimento do dia e a pluviosidade. Como o clima parece ser pouco limitante para as espécies na área de estudo, talvez a seleção atue no sentido de diminuir a predação das sementes, favorecendo espécies que frutifiquem no período mais frio e seco do ano, momento de menor atividade de patógenos e predadores. Rathcke \& Lacey (1985) afirmam que a queda de frutos no período de menor atividade dos predadores e patógenos reduziria a mortalidade das sementes.

Fenofases relacionadas a determinadas épocas do ano: brotamento e floração - Mesmo tendo espécies com folhas novas o ano todo, o brotamento foi a fenofase mais sazonal quando considerados os $26 \%$ mínimos de ocorrência. O brotamento, tanto geral como o para os $26 \%$ mínimos de ocorrência, não apresentou correlações positivas significativas com a pluviosidade, que parece não ser um fator limitante ao brotamento. Por outro lado, esta fenofase apresentou correlação positiva significativa com a temperatura e com o comprimento do dia, sugerindo que os aumentos no fotoperíodo, associados a aumentos na temperatura, sejam fatores indutores do brotamento. Diversos estudos fenológicos sugerem que aumentos no fotoperíodo e na temperatura podem induzir o brotamento em árvores tropicais (Daubenmire 1972, Frankie et al. 1974a, Alvin \& Alvin 1976, Mori et al. 1982, Longman \& Jenik 1987, Morellato et al. 1989). Segundo Wright \& van Shaik (1994), espécies limitadas pela luz produzem novas folhas e flores durante a estação de irradiação máxima, quando a água está disponível o ano todo. 
O brotamento foi muito concentrado em algumas espécies, o que pode ser uma estratégia de escape aos animais fitófagos. De uma maneira geral, segundo Aide $(1988,1992)$ e van Shaik et al. (1993), as folhas produzidas durante brotamentos mais concentrados sofrem uma menor taxa de predação, podendo ser esta uma pressão seletiva para a concentração do brotamento em algumas espécies. Em muitas espécies, a queda foliar precedeu ao brotamento. A queda de folhas pode ser um fator indutor do brotamento em algumas espécies, pois esta reduziria a perda de água pela planta, levando à reidratação dos ramos sem folhas e produção de folhas, mesmo em períodos secos (Reich \& Borchert 1984).

A floração em Picinguaba foi mais intensa durante o longo período mais quente e úmido, a semelhança do que ocorre em duas matas úmidas brasileiras: uma na Bahia (Mori et al. 1982) e outra no Rio de Janeiro (Costa et al. 1992). Os trabalhos realizados em regiões neotropicais sujeitas à pluviosidade sazonal normalmente apontam o pico de floração na estação seca (Janzen 1967, Araujo 1970, Frankie et al. 1974, Fournier 1976, Jackson 1978) ou no período de transição entre a estação seca e a estação úmida (Koptur et al. 1988, Morellato et al. 1989, Morellato 1991, 1995). Já ambientes com baixa sazonalidade climática, como a floresta úmida pré-montana localizada na Colômbia Pacífica, apresentam números semelhantes de espécies em flor durante o ano todo (Hilty 1980).

Embora a floração não tenha apresentado forte sazonalidade na floresta de planície de Picinguaba, como evidenciado pela pequena concentração das espécies (r) em torno da data média, apresentou correlacão significativa com o comprimento do dia e temperatura. No estudo desenvolvido por Mori et al. (1982) numa mata higrófila sul-baiana, sem estação seca definida, o pico da atividade reprodutiva também coincidiu com o aumento do fotoperíodo e da temperatura. Morellato et al. (1989) e Morellato (1991) sugerem que a floração seria desencadeada pelo aumento do fotoperíodo, temperatura e umidade na transição da estação seca para a úmida.

Dentre os fatores bióticos, a polinização deve ter um papel fundamental na regulação da época de floração das espécies na floresta de planície de Picinguaba. Borchert (1983) comenta que, quando se analisa o comportamento da floração em espécies tropicais, é importante considerar que estes padrões devem ser explicados como resultado do contexto geral de desenvolvimento da árvore determinado por fatores climáticos, edáficos e bióticos.

Comparação com florestas semidecíduas - O pequeno número de espécies decíduas e semidecíduas (8,7\% ao todo) encontradas na vegetação arbórea de planície litorânea de Picinguaba parece confirmar a sugestão de Davies (1945), de que em climas mais úmidos a porcentagem de espécies decíduas cai para cerca de $10 \%$. Costa et al. (1992) também encontraram, para a Mata Atlântica de altitude, maioria de árvores não decíduas. Provavelmente, a baixa sazonalidade do ambiente permite que a maioria das espécies perca poucas folhas ao longo de todo o ano. Morellato \& Leitão-Filho (1992) encontraram $48 \%$ e $40 \%$ das espécies decíduas e semidecíduas, respectivamente, na floresta de altitude e na floresta mesófila, na Serra do Japi, e Morellato (1995) encontrou $55 \%$ de espécies decíduas e semidecíduas na Fazenda Santa Genebra, ambos em florestas semidecíduas do interior do estado de São Paulo. Segundo Morellato (1991), em florestas semidecíduas do sudeste do Brasil, a presença de grande porcentagem de espécies decíduas seria uma adaptação à sazonalidade ambiental, expressa pela alternância entre as estações seca e úmida, o que não ocorre na planície litorânea atlântica estudada. Ao contrário da floresta de planície deste estudo, onde a queda de folhas foi constante ao longo do ano, com r não significativo, em duas florestas da Serra do Japi a queda foliar apresentou $\mathrm{r}$ significativo e elevado para esta fenofase (Morellato et al. 1989), reforçando a idéia de deciduidade relacionada a estacionalidade climática discutida anteriormente.

A tendência geral de um fluxo de folhas sazonal seria um traço das florestas tropicais sazonais (Longman \& Jenik 1987), e das florestas semidecíduas do sudeste do Brasil (Morellato et al. 1989, Morellato 1991, 1995). A baixa sazonalidade do brotamento diferencia claramente a floresta atlântica estudada das florestas semidecíduas acima citadas. As espécies arbóreas da floresta de planície litorânea de Picinguaba apresentaram sazonalidade menor, não só na queda foliar e no brotamento, como também na produção de flores e frutos, se comparadas com as florestas semidecíduas do interior do estado. Embora as datas médias das fenofases brotamento para os 
$26 \%$ mínimos de ocorrência $(\mathrm{r}=0,39)$, floração $(\mathrm{r}=$ $0,22)$ e frutificação $(r=0,18)$ obtidas através do teste de Rayleigh fossem significativas, os valores de $r$ foram bem inferiores aos valores de $r$ encontrados por Morellato et al. (1989) para as mesmas fenofases, em floresta semidecídua da Serra do Japi, respectivamente, 0,$80 ; 0,54$ e 0,38 . A concentração de espécies em torno da data média não é tão marcante como a encontrada para esta floresta semidecídua. Entretanto, no mesmo estudo, Morellato et al. (1989) observaram que a floresta de altitude da Serra do Japi apresenta valores de $r$ para brotamento $(r=0,32)$, floração $(r=0,24)$ e frutificação $(r=0,21)$, inferiores aos da floresta semidecídua. Segundo Morellato et al. (1989), os valores de $\mathrm{r}$ mais altos na floresta semidecídua refletem a maior sazonalidade neste ambiente, quando comparado com a floresta de altitude, onde a umidade é maior e a estação seca é menos pronunciada. Os valores de $\mathrm{r}$ encontrados para floresta de planície litorânea do Núcleo Picinguaba se aproximam aos encontrados para a mata de altitude da Serra do Japi, mais úmida, reforçando a idéia da tendência à menor influência de fatores climáticos em ambientes menos sazonais.

Em Picinguaba, $87 \%$ das espécies apresentaram dispersão por animais enquanto na Serra do Japi cerca de $70 \%$ das espécies para as duas florestas são zoocóricas (Morellato \& Leitão-Filho 1992) e na Santa Genebra $56 \%$ das arbóreas e arbustivas são dispersas por animais (Morellato 1991, 1995). Segundo Morellato \& Leitão-Filho (1992, 1996), as espécies dispersas pelo vento geralmente frutificam no melhor período para disseminar seus diásporos, sendo que vários autores associam o maior número de espécies anemocóricas com o período mais seco em florestas tropicais sazonais (Janzen 1967, Croat 1975, Morellato \& Leitão-Filho 1992, 1996). Segundo Janzen (1967), a baixa umidade relativa do período seco seria importante na dispersão dos diásporos dispersos pelo vento. O clima em Picinguaba, com umidades relativas sempre altas, mesmo no período menos úmido, não favoreceria a dispersão dos diásporos pelo vento. Morellato (1991) encontrou relação entre precipitação, sazonalidade climática e porcentagem de espécies dispersas pelo vento em várias florestas neotropicais: quanto menor a precipitação anual e maior a sazonalidade climática, maior a porcentagem de espécies com frutos dispersos pelo vento.

Este trabalho mostra que os padrões fenológicos em floresta atlântica de planície litorânea apresentam, de forma geral, padrões sazonais menos acentuados do que aqueles observados em florestas semidecíduas, com picos de floração e brotamento na estação úmida, associados à temperatura e comprimento do dia. As características ecológicas das espécies também se modificam, apresentando uma maior proporção de dispersão por animais, menor ocorrência de dispersão pelo vento e pequena porcentagem de espécies decíduas, quando comparadas com florestas semidecíduas. Este estudo evidencia a diferença na dinâmica sazonal das florestas semidecíduas e de planície atlântica, porém estudos em outras áreas de vegetação atlântica, especialmente em floresta atlântica de encosta, mais típica, são necessários para confirmar ou não estas tendências.

Agradecimentos - As autoras agradecem a E.C. Romera pelo apoio no trabalho de campo, a O. Cesar e R. Monteiro, por permiterem acesso a dados não publicados e a dois assessores anônimos, pelas sugestões; ao Instituto Florestal por permitir a realização dos estudos na área do Núcleo Picinguaba e aos funcionários do Núcleo pelo apoio logístico no local; à FAPESP pelo apoio financeiro (proc. no. 93/3604-9). D.C. Talora recebeu bolsa de mestrado da CAPES. Este trabalho é uma contribuição do Grupo de Fenologia de Plantas e Dispersão de Sementes apoiada pela FAPESP (95/9626-0). L.P.C. Morellato agradece ao $\mathrm{CNPq}$ pela bolsa de produtividade em pesquisa.

\section{Referências bibliográficas}

AIDE, T.M. 1988. Herbivory as a selective agent on the timing of leaf production in a tropical understory community. Nature 336:574-575.

AIDE, T.M. 1992. Dry season leaf production: an escape from herbivory. Biotropica 24:532-537.

ALENCAR, J.C., ALMEIDA, R.A. \& FERNANDES, N.P. 1979. Fenologia de espécies florestais em floresta tropical úmida de terra firme da Amazônia Central. Acta Amazonica 1:63-97.

ALVIM, P.T. \& ALVIM, R. 1976. Relation of climate to growth periodicity in tropical trees. In Tropical trees as living systems (P.B. Tomlinson \& M.H. Zimmermann, eds.). Cambridge Univ. Press, Cambridge, p.455-464.

ARAUJO, V.C. 1970. Fenologia de essências florestais amazônicas I. Boletim do INPA 4:1-25. 
BORCHERT, R. 1980. Phenology and ecophysiology of tropical trees: Erythrina poeppigiana O.F. Cook. Ecology 61:1065-1074.

BORCHERT, R. 1983. Phenology and control of flowering in tropical trees. Biotropica 15:81-89.

BULLOCK, S.H. \& SOLÍS-MAGALLANES, A. 1990. Phenology of canopy trees of a tropical deciduous forest in Mexico. Biotropica 22:22-35.

CESAR, O. \& MONTEIRO, R. 1995. Florística e fitossociologia de restinga em Picinguaba (Parque Estadual da Serra do Mar), município de Ubatuba, SP. Naturalia 20:89-105.

COSTA, M.L.M.N., PEREIRA, T.S. \& ANDRADE, A.C.S. 1992. Fenologia de algumas espécies de Mata Atlântica, Reserva Ecológica de Macaé de Cima (estudo preliminar). Revista do Instituto Florestal 4:226-232.

CROAT, T.B. 1975. Phenological behavior of habit and habitat classes on Barro Colorado Island (Panama Canal Zone). Biotropica 7:270-277.

DAUBENMIRE, B. 1972. Phenology and other characteristics of tropical semideciduous forest in NorthWestern Costa Rica. Journal of Ecology 60:147-170.

DAVIES, D.E. 1945. The annual cycle of plants, mosquitoes, birds, and mammals in two brazilian forests. Ecological Monographs 15:245-295.

FOURNIER, L.A. 1976. Observaciones fenológicas en el bosque humedo premontano de San Pedro de Montes Oca, Costa Rica. Turrialba 26:54-59.

FOURNIER, L.A. \& CHARPANTIER, C.O. 1975. El tamaño da amostra y la frecuencia de las observaciones en el estudio de las característica fenologicas de los árboles tropicales. Turrialba 25:45-48.

FOURNIER, L.A. \& SALAS, S. 1966. Algunas observaciones sobre la dinamica de la floracion en el bosque humedo de Villa Collon. Revista de Biologia Tropical 14:75-85.

FRANKIE, G.W., BAKER, H.G. \& OPLER, P.A. 1974. Comparative phenological studies of trees in tropical lowland wet and dry forest sites of Costa Rica. Journal of Ecology 62:881-913.

HILTY, S.L. 1980. Flowering and fruiting periodicity in a premontane rain forest in pacific Colombia. Biotropica 12:292-306.

JACKSON, J.F. 1978. Seasonality of flowering and leaffall in brazilian subtropical lower montane moist forest. Biotropica 10:38-42.

JANZEN, D.H. 1967. Synchronization of sexual reproduction of trees within the dry season in Central America. Evolution 21:620-37.

JOLY, A.C., LEITÃO-FILHO, H.F. \& SILVA, S.M. 1992. O patrimônio forístico. In Mata Atlântica. Editora Index Ltda e Fundação Mata Atlântica, São Paulo, p.97-107.
KOEPPEN, W. 1948. Climatologia: con un estudio de los climas de la tierra. México.

KOPTUR, S., HABER, W.A., FRANKIE, G.W. \& BAKER, H.G. 1988. Phenological studies of shrub and treelet species in tropical cloud forests of Costa Rica. Journal of Tropical Ecology 4:347-359.

LAMPE, M.G., BERGERON, Y., MCNEIL, R. \& LEDUC, A. 1992. Seasonal flowering and fruiting patterns in tropical semi-arid vegetation of northeastern Venezuela. Biotropica 24:64-76.

LEITÃO-FILHO, H.F. 1992. A flora arbórea da Serra do Japi. In História natural da Serra do Japi: ecologia e preservação de uma área no Sudeste do Brasil (L.P.C. Morellato, org.). Editora da Unicamp, Campinas. p.40-63.

LIETH, H. 1974. Purpose of a phenology book. In Phenology and seasonality modeling. (H. Lieth, ed.). Springer, Berlin, p.3-19.

LONGMAN, K.A. \& JENIK, J. 1987. Tropical forest and its environment. Longman Singapore, Singapore.

MONASTERIO, M. \& SARMIENTO, G. 1976. Phenological strategies of plant species in the tropical savanna and semi-deciduous forest of the Venezuelan Llanos. Journal of Biogeography 3:325-356.

MORELLATO, L.P.C. 1991. Fenologia de árvores, arbustos e lianas em uma floresta semidecídua no sudeste do Brasil. Tese de doutorado, Universidade de Campinas, Campinas.

MORELLATO, L.P.C. 1995. As estações do ano na floresta. In Ecologia e preservação de uma floresta tropical urbana (P.C. Morellato \& H.F. Leitão-Filho, orgs). Editora da Unicamp, Campinas, p. 37-41.

MORELLATO, L.P.C. \& LEITÃO-FILHO, H.F. 1990. Estratégias fenológicas de espécies arbóreas em floresta mesófila na Serra do Japi, Jundiaí, SP. Revista Brasileira de Biologia 50:163-173.

MORELLATO, L.P.C. \& LEITÃO-FILHO, H.F. 1992. Padrões de frutificação e dispersão na Serra do Japi. In História natural da Serra do Japi: ecologia e preservação de uma área florestal no Sudeste do Brasil (L.P.C. Morellato, org.). Editora da Unicamp/Fapesp, Campinas, p.112-140.

MORELLATO, L.P.C. \& LEITÃO-FILHO, H.F. 1996. Reproductive phenology of climbers in a Southeasthern Brazilian forest. Biotropica 28:180-191.

MORELLATO, L.P.C., RODRIGUES, R.R., LEITÃOFILHO, H.F. \& JOLY, C.A. 1989. Estudo fenológico comparativo de espécies arbóreas de floresta de altitude e floresta mesófila semidecídua na Serra do Japi, Jundiaí, SP. Revista Brasileira de Botânica 12:85-98. 
MORELLATO, L.P.C., LEITÃO-FILHO, H.F. RODRIGUES, R.R., \& JOLY, C.A. 1990. Estratégias fenológicas de espécies arbóreas em floresta de altitude na Serra do Japi, Jundiaí, SP. Revista Brasileira de Biologia 50:149-162.

MORI, S.A., BOOM, B.M. \& PRANCE, G.T. 1981. Distributional patterns and conservation of eastern brasilian coastal forest tree species. Brittonia 33:233245.

MORI, S.A.; LISBOA, G. \& KALLUNKI, J.A. 1982. Fenologia de uma mata higrófila sul-baiana. Revista Theobroma 12:217-230.

OPLER, P.A., FRANKIE, G.W. \& BAKER, H.G. 1980. Comparative phenological studies of treelet and shrub species in tropical wet and dry forests in the lowlands of Costa Rica. Journal of Ecology 68:189209.

PIRES-O'BRIEN, M.J. 1993. Phenology of tropical trees from Jari, lower amazon, I. phenology of eight forest communities. Boletim do Museu Paraense Emílio Goeldi 9:67-92.
RATHCKE, B. \& LACEY, E.P. 1985. Phenological patterns of terrestrial plants. Annual Review of Ecology and Systematics 16:179-214.

REICH, P.B. \& BORCHERT, R. 1984. Water stress and tree phenology in a tropical dry forest in the lowlands of Costa Rica. Journal of Ecology 72:61-74.

SNOW, D.W. 1965. A possible selective factor in the evolution of fruiting seasons in tropical forest. Oikos 15:274-281.

STEEGE, H. \& PERSUAD, C.A. 1991. The phenology of guyanese timber species: a compilation of a century of observations. Vegetatio 95:177-198.

VAN SCHAIK, C.P., TERBORGH, J.W. \& WRIGHT, S.J. 1993. The phenology of tropical forests: adaptative significance and consequences for primary consumers. Annual Review of Ecology and Systematics 24:353 -377.

WRIGHT, S.J. \& VAN SHAIK, C.P. 1994. Light and the phenology of tropical trees. American Naturalist 143:192-199.

ZAR, J.H. 1996. Bioestatistical analysis. Prentice-Hall, New Jersey. 